\title{
OS IMPACTOS PROVOCADOS COM AGROTÓXICOS USADOS PELO AGRONEGÓCIO CANAVIEIRO SOBRE OS CAMPONESES SERICICULTORES E DEMAIS PRODUTORES DO ASSENTAMENTO BETEL E COMUNIDADE ESTRELINHA EM GLÓRIA DE DOURADOS - MS
}

\author{
Recebido em 10/12/2020, aprovado em 6/03/2020 \\ 10.30612/mvt.v6i11.10803 \\ Cleidivaldo Siqueira Pereira ${ }^{5}$ \\ Rodrigo Simão Camacho ${ }^{6}$
}

\begin{abstract}
RESUMO: Este trabalho busca analisar as resistências dos camponeses frente à territorialização da cana no assentamento Betel - Glória de Dourados - MS, de modo que nossa pesquisa está fundamentada, a partir de uma análise teórica com autores que discutem o paradigma da questão agrária no campo, bem como, foi realizado o trabalho de campo através do diálogo e registros junto aos camponeses assentados. Verificamos que estes estáo cercados pelo avanço canavieiro na localidade, fato que tem provocado dificuldades no desenvolvimento de várias atividades. Este processo acarretou em vários impactos territoriais para estes sujeitos, como a perda da produção de alimentos, perda de animais, a perda da biodiversidade, a intoxicaçáo pelo uso dos agrotóxicos passados nas lavouras de cana, de modo que este é um dos principais impactos socioterritoriais abordado em nosso trabalho. Essa realidade pode ser observada a partir da atividade desenvolvida por alguns sericicultores (produtores do bicho-da-seda) dentro do assentamento, onde a luta e resistência se torna o grande trunfo frente à expansão canavieira naquela localidade.
\end{abstract}

Palavras-chave: Camponeses; Territorialização canavieira; Agrotóxicos.

\footnotetext{
5 Possui graduação em Geografia pela Universidade Estadual de Mato Grosso do Sul (2011). Graduação em História pelo Centro Universitário de Jales. Especializaçáo em Educação do Campo pela Universidade Federal de Mato Grosso Do Sul (2016). Mestrado em Geografia pela Universidade Federal da Grande Dourados (2019). Atualmente é professor convocado da rede estadual e municipal de ensino. Tem experiência na área de Geografia e História, com ênfase em Geografia Agrária.

6 Possui graduação em Geografia (2005) e Mestrado em Geografia (2008) pela Universidade Federal de Mato Grosso do Sul; Doutorado em Geografia pela Universidade Estadual Paulista (UNESP) campus de Presidente Prudente (2014); Pós-Doutorado em Geografia pela Universidade Federal de Mato Grosso do Sul (2015). Atualmente é Docente no Curso de Licenciatura em Educaçáo do Campo (LEDUC) e no Programa Pós-Graduação Interdisciplinar em Educação e Territorialidade (PPGET) na Faculdade Intercultural Indígena (FAIND) da Universidade Federal da Grande Dourados (UFGD). Docente permanente dos Programas de Pós-Graduação em Geografia na Faculdade de Ciências Humanas (FCH) da UFGD e na Universidade Federal de Mato Grosso Sul (UFMS) campus de Três Lagoas. Líder do Grupo de Estudos, Pesquisas e Projetos de Geografia, Educação do Campo e Questão Agrária (GEOEDUQA) - UFGD.
} 


\title{
THE IMPACTS OF AGROTOXIC USED BY THE CANAVIEIRO AGRIBUSINESS ON THE SERICICULTURAL AND OTHER PRODUCERS OF THE BETEL SETTLEMENT AND THE STAR-GOLDEN GLORY STAR COMMUNITY
}

\begin{abstract}
This paper seeks to analyze the resistance of peasants to the sugarcane territorialization in the Bethel - Glória de Dourados - MS settlement, so that our research is based on a theoretical analysis with authors who discuss the paradigm of agrarian issues in the field, as well as as, fieldwork was carried out through dialogue and records with the settled peasants. We verified that these are surrounded by the sugarcane advance in the locality, fact that has caused difficulties in the development of various activities. This process has caused several territorial impacts for these subjects, such as loss of food production, loss of animals, loss of biodiversity, intoxication from the use of past pesticides in sugarcane crops, so this is one of the main socio-territorial impacts. addressed in our work. This reality can be observed from the activity developed by some sericulturists (silkworm producers) within the settlement, where the struggle and resistance becomes the great asset against the sugarcane expansion in that locality.
\end{abstract}

Keywords: Peasants; Sugarcane territorialization; Pesticides.

\section{LOS IMPACTOS DE AGROTOXICOS UTILIZADOS POR LA AGRICULTURA DE CANAVIEIRO EN LOS PRODUCTORES SERICICULTURALES Y DE OTRO TIPO DEL CONVENIO BETEL Y LA COMUNIDAD STAR - GOLDEN GLORY STAR}

RESUMEN: Este artículo busca analizar la resistencia de los campesinos a la territorialización de la cańa de azúcar en el asentamiento de Bethel - Glória de Dourados - MS, para que nuestra investigación se base en un análisis teórico con autores que discutan el paradigma de los problemas agrarios en el campo, así como como, el trabajo de campo se llevó a cabo a través del diálogo y los registros con los campesinos establecidos. Verificamos que estos están rodeados por el avance de la caña de azúcar en la localidad, hecho que ha causado dificultades en el desarrollo de diversas actividades. Este proceso ha causado varios impactos territoriales para estos temas, como la pérdida de producción de alimentos, pérdida de animales, pérdida de biodiversidad, intoxicación por el uso de pesticidas pasados en cultivos de caña de azúcar, por lo que este es uno de los principales impactos socio-territoriales. abordado en nuestro trabajo. Esta realidad se puede observar a partir 
de la actividad desarrollada por algunos sericulturistas (productores de gusanos de seda) dentro del asentamiento, donde la lucha y la resistencia se convierten en el gran activo contra la expansión de la cańa de azúcar en esa localidad.

Palavras Clave: Campesinos; Territorialización de la cańa de azúcar; Pesticidas.

A sericicultura, uma das atividades desenvolvidas dentro do assentamento betel, encontra algumas barreiras devido ao monocultivo da cana, ou seja, a utilizaçáo de agrotóxicos realizada no cultivo canavieiro tem prejudicado muito a produção do bicho-da-seda, prejuízos aos sericicultores não só do assentamento, mas também de outros, o que tem apresentado graves problemas aos produtores da região, como relata $\mathrm{P}$, sericicultor do assentamento Betel.

[...] quando nóis chegamo aqui não tinha a cana ainda, mais tinha o soja e a pecuária, só que o soja não tinha problema pra sericicultura, já criadores do bicho-da-seda aqui na regiáo antes nunca tinham tido problema com veneno, a cana aumentou aqui a partir de 2013, 2014, nóis foi ter problema mesmo em 2015 quando eles intensificou a pulverização aérea, foi quando chegou o aviāo 7 .

O uso de agrotóxicos é uma das alternativas muito praticadas pelos produtores/agricultores nos últimos anos, principalmente a partir dos avanços da tecnologia, que consequentemente proporcionou os avanços da atividade no campo.

Desse modo, para que possamos debater as práticas e o uso de agrotóxicos, primeiramente, precisamos compreender o seu conceito e seus propósitos no campo. A Lei 7.802/1989 regulamenta o uso de agrotóxicos e os define como:

Os produtos e os agentes de processos físicos, químicos ou biológicos, destinados ao uso nos setores de produção, no armazenamento e beneficiamento de produtos agrícolas, nas pastagens, na proteção de florestas, nativas ou implantadas, e de outros ecossistemas e também de ambientes urbanos, hídricos e industriais, cuja finalidade seja alterar a composição da flora ou da fauna, a fim de preservá-las da ação danosa de seres vivos considerados nocivos; assim como substâncias e produtos, empregados como desfolhantes, dessecantes, estimuladores e inibidores de crescimento (BRASIL, 2016) ${ }^{8}$.

É preciso compreender quais foram os motivos e propósitos que levaram a intensificação do uso de agrotóxicos, ou seja, historicamente, tais produtos promoveram mudança no cenário da produção de alimentos (BRASIL, 2016) representando uma revolução tecnológica que prometia acabar com o problema da fome mundial.

Desse modo, através do monocultivo da cana, e a intensificação do uso de agrotóxicos, tem dificultado muito a produção do bicho-da-seda, prejuízos aos sericicultores não só do assentamento,

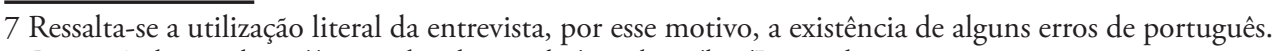
8 Disponível em: <http://www.planalto.gov.br/ccivil_03/leis/L7802.htm>. 
mas também de outros camponeses de comunidades da regiáo que também praticam tal atividade. Importante observar o aumento significativo do consumo e uso desses produtos na América Latina, e mais especificamente no Brasil, como comenta Rigotto e Rosa:

$\mathrm{Na}$ América Latina, um importante e crescente mercado dentro do contexto mundial, o faturamento líquido na venda de agrotóxicos cresceu $18,6 \%$ de 2006 a 2007, e 36,2\% de 2007 a 2008 (Sindicato Nacional da Indústria de Produtos para Defesa Agrícola, 2009). Desde 2008, o Brasil tornou-se o maior consumidor mundial de agrotóxicos, movimentando 6,62 bilhóes de dólares em 2008 para um consumo de 725,6 mil toneladas de agrotóxicos - o que representa 3,7 quilos de agrotóxicos por habitante (RIGOTTO; ROSA, 2012, p.89).

Um estudo realizado mais recente por Bombardi (2017), quanto a venda de agrotóxico, em relação aos tipos de culturas no Brasil, mostra que a expansão das atividades agrícolas, principalmente pela monocultura da soja, do milho e da Cana-de-açúcar tem influenciado e incentivado consideravelmente o uso desses produtos. A autora apresenta alguns dados significativos em relaçáo ao que vem sendo cultivado.

De acordo com a autora, em 2015, a soja ocupou o primeiro lugar como destino total das vendas de agrotóxicos no país (52\%), o milho e a cana mantiveram o mesmo percentual, com $10 \%$ do consumo total. Esses dados ficam mais evidentes quando apresentados em gráfico, (Gráfico 01) onde cada cultura apresenta seu poderio de influência na aplicaçáo e incentivos para as vendas e consumos de agrotóxicos, como demonstrado por Bombardi (2017, p.34).

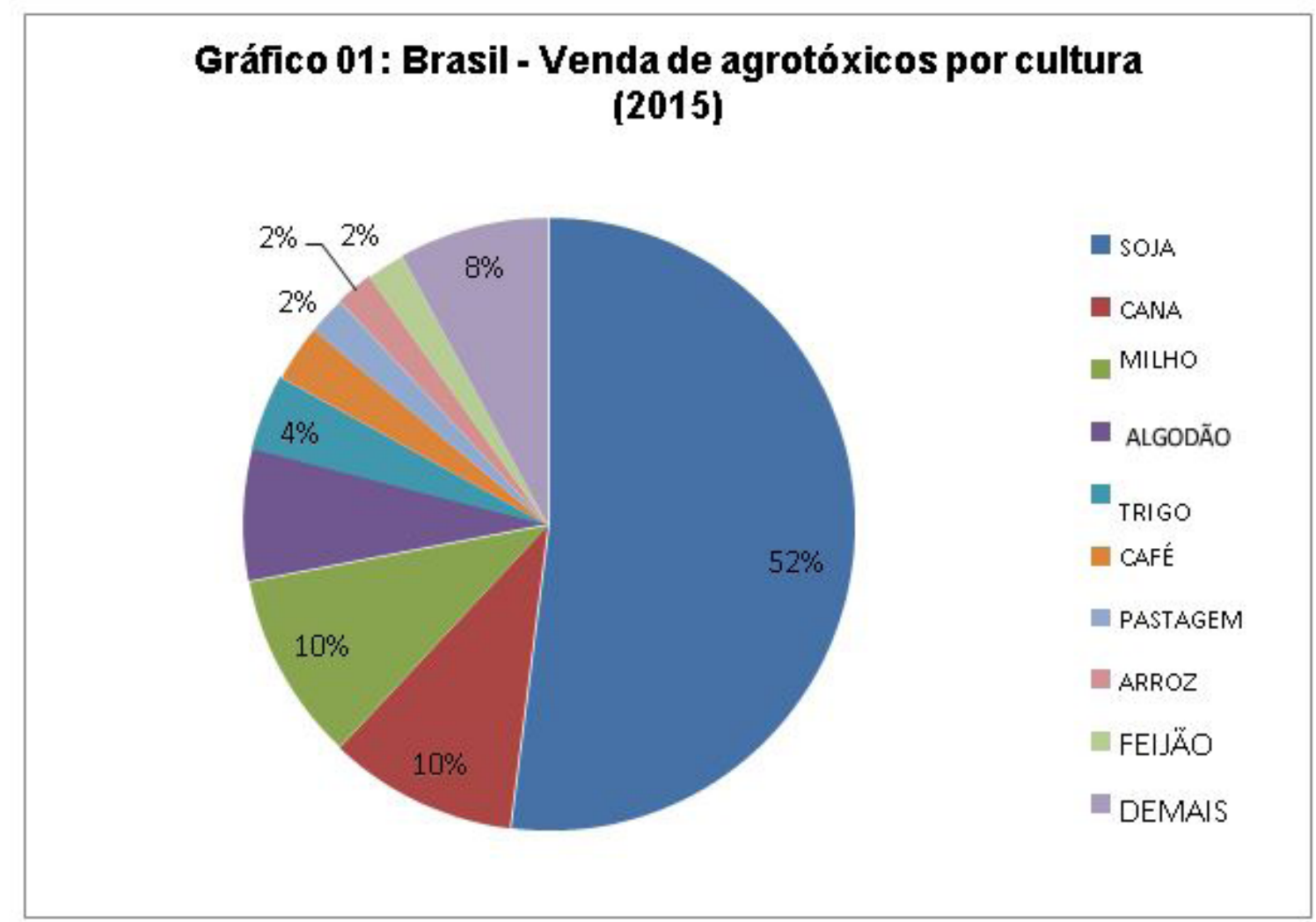

Fonte: SINDIVEG, Bombardi, M.L - DIEESE (p.34, 2017) org. Cleidivaldo Siqueira Pereira. 
Importante destacar o grande predomínio da soja no Brasil que, atualmente, ocupa mais de 30 milhôes de hectares do solo brasileiro, sozinha, responsável por mais da metade do volume de agrotóxicos comercializado no país. Para estes três cultivos (soja, milho e cana) convergem $72 \%$ de todo agrotóxico comercializado. Desse modo, dois terços do montante de agrotóxicos comercializados no país têm como receptáculo três culturas expoentes da agricultura capitalista brasileira.

Por outro lado, nas pequenas propriedades, a alimentação do bicho-da-seda (foto 01) é produzida na própria propriedade (menor custo). A amoreira é uma planta rústica, adaptada aos mais diferentes climas, podendo ser produzida em todo país, sua produção exige pouco esforço físico, sendo ainda uma maneira de ocupar a mão-de-obra ociosa no campo.

Foto 01 - Sericicultor do assentamento Betel - Glória de Dourados

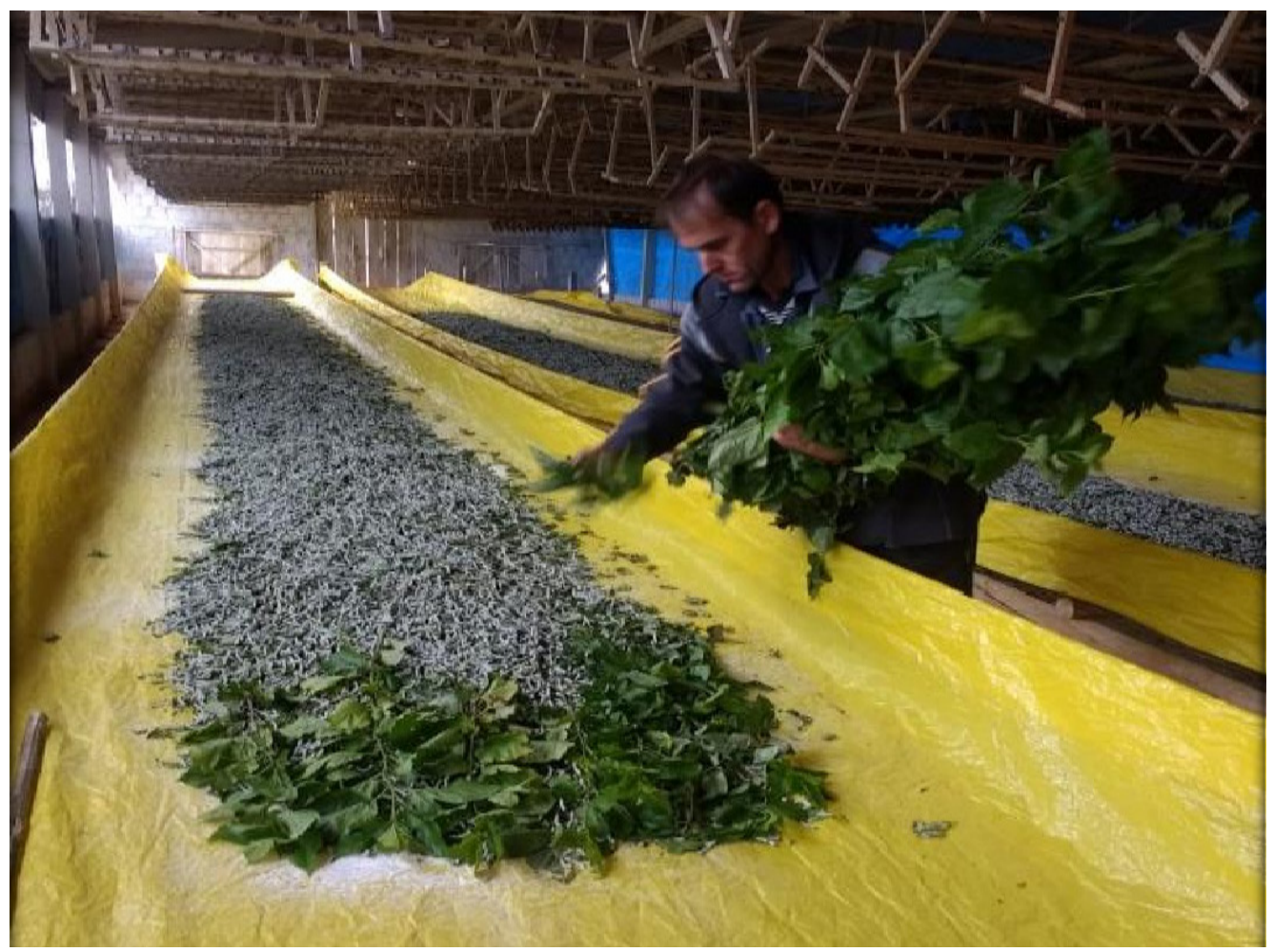

Fonte: PEREIRA (2018).

Entretanto, não apenas os sericicultores, mas também outros agricultores camponeses, como é o casso dos apicultores de Glória de Dourados e regiâo, vêm sendo afetados pelos impactos causados pela deriva da pulverização aérea de agrotóxicos que acontecem nas extensas áreas de lavouras de cana-de-açúcar que circundam o município. Os prejuízos dos sericicultores já são grandes, com a mortalidade do bicho-da-seda em áreas afetadas.

Neste sentido, para que pudéssemos compreender e debater melhor tais disputas e conflitos que evolvem a questão agrária em nosso recorte territorial local foi necessário um estudo teórico e prático. Iremos debater sobre a territorialização da produção canavieira e seus impactos socioterritoriais com destaque para o uso intensivo de agrotóxicos e a expropriaçáo de trabalhadores rurais locais.

Dessa maneira, para que possamos melhor compreender a realidade a ser debatida neste trabalho, apresentamos a imagem abaixo (foto 02) com relaçáo aos limites do assentamento betel e o cultivo da cana em seu entorno, além do mapa de localização (mapa 01) do assentamento Betel no município de Glória de Dourados. 
Foto: 02 - Limites territoriais entre o Assentamento Betel e a Monocultura Canavieira

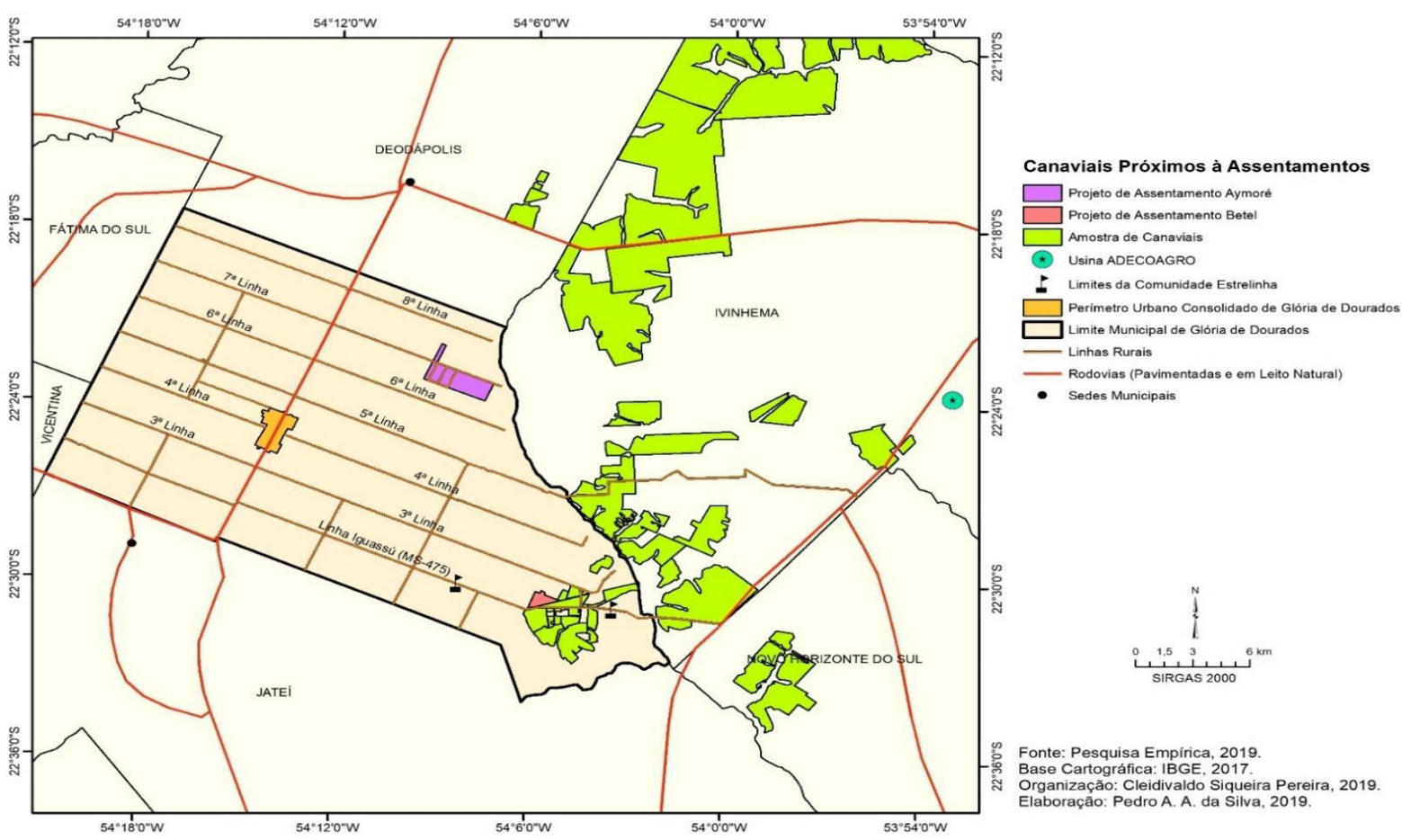

Fonte: Pereira, C. S (2019).

Além disso, buscamos identificar a presença marcante da cana-de-açúcar no entorno do assentamento. Ao evidenciarmos a localização do assentamento Betel e seu entorno, entendemos que seria interessante, apresentar a existência de um outro assentamento (Aymoré), dentro dos limites do município de Glória de Dourados, somente para registrar que este também sofre os impactos causados pela produção canavieira. Ressaltamos, entretanto, que se trata apenas de dados complementares, visto que, não nos propomos a pesquisar o Aymoré. Embora este assentamento não esteja tão próximo das áreas cultivadas com cana, mesmo assim, sofre alguns impactos.

Mapa 01 - Canaviais no entorno do assentamento Betel e adjacências

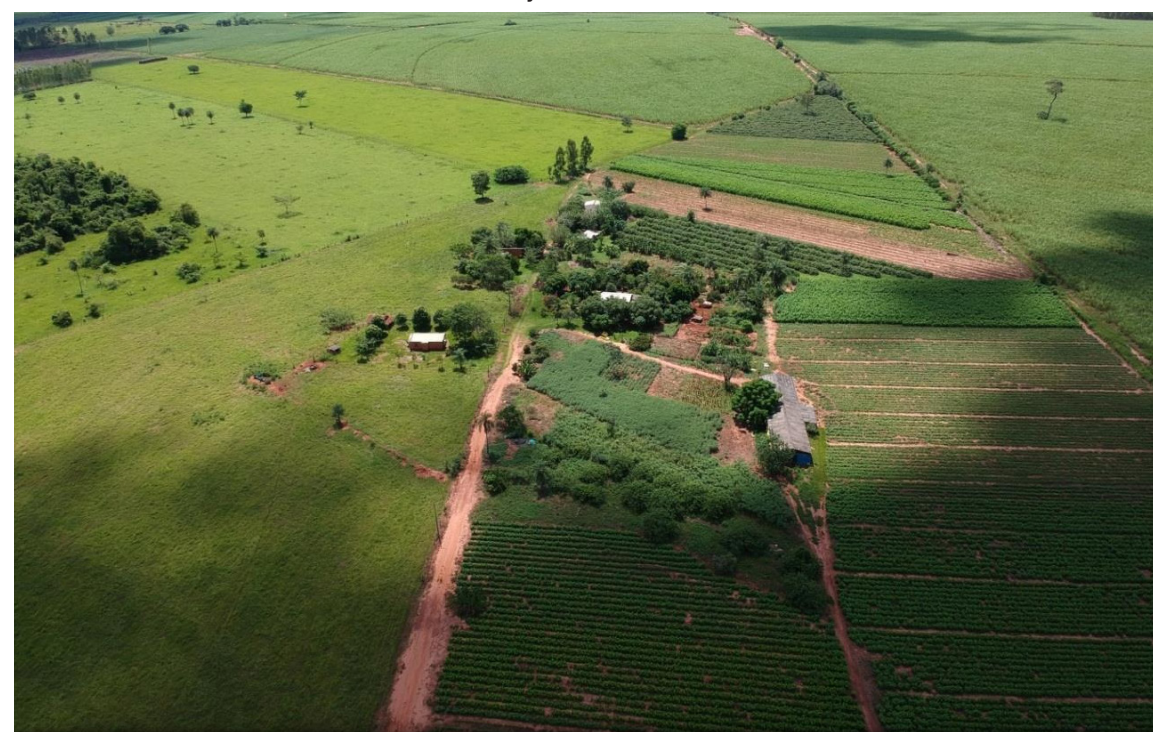

Fonte: Pereira, C. S (2019). 
Podemos observar que a presença da cana é bem marcante nas proximidades dos assentamentos e nos limites da comunidade Estrelinha, (vejamos a foto 05 abaixo) composta de camponeses-tradicionais que residem neste local há mais de trinta anos. Contudo, mesmo que nossa delimitação territorial esteja centralizada no assentamento Betel, entendemos ser relevante discutir também as relaçôes socioterritoriais desses agricultores tradicionais.

Os danos à sericicultura constatados no município de Glória de Dourados foram tâo significativos que muitos criadores do bicho-da-seda abandonaram a atividade, em decorrência da contaminação de sua cadeia de produção pelos agrotóxicos utilizados na monocultura de cana-de-açúcar, especialmente em função da pulverização aérea de tais produtos, ou seja, de acordo com a lei no 917 , de 7 de outubro de 1969 (BRASIL, 1969), que dispóe sobre o emprego da aviação agrícola no país, e pelo Decreto no 86.765, de 22 de dezembro de 1981 (BRASIL, 1981).

O tema da pulverização aérea (foto 03) de agrotóxicos tornou-se polêmico por apresentar vantagens e desvantagens em sua aplicação. Os que defendem essa atividade citam os seguintes benefícios: rapidez de execução, permitindo tratar grandes áreas no momento correto; uniformidade de deposição dos produtos aplicados; ausência de danos diretos ("amassamento") das plantas da cultura; inexistência de danos indiretos, como a compactação do solo; possibilidade de uso em praticamente qualquer condição de solo (solos irrigados ou encharcados por chuvas, por exemplo); menor número de pessoas envolvidas, o que é vantajoso quando se trata de aplicação de produtos tóxicos; participação obrigatória de pessoal especializado (técnicos, pilotos, agrônomos) (COSTA, 2017, p.10).

Foto: 03 - Aeronave sobrevoando nas proximidades do assentamento Betel

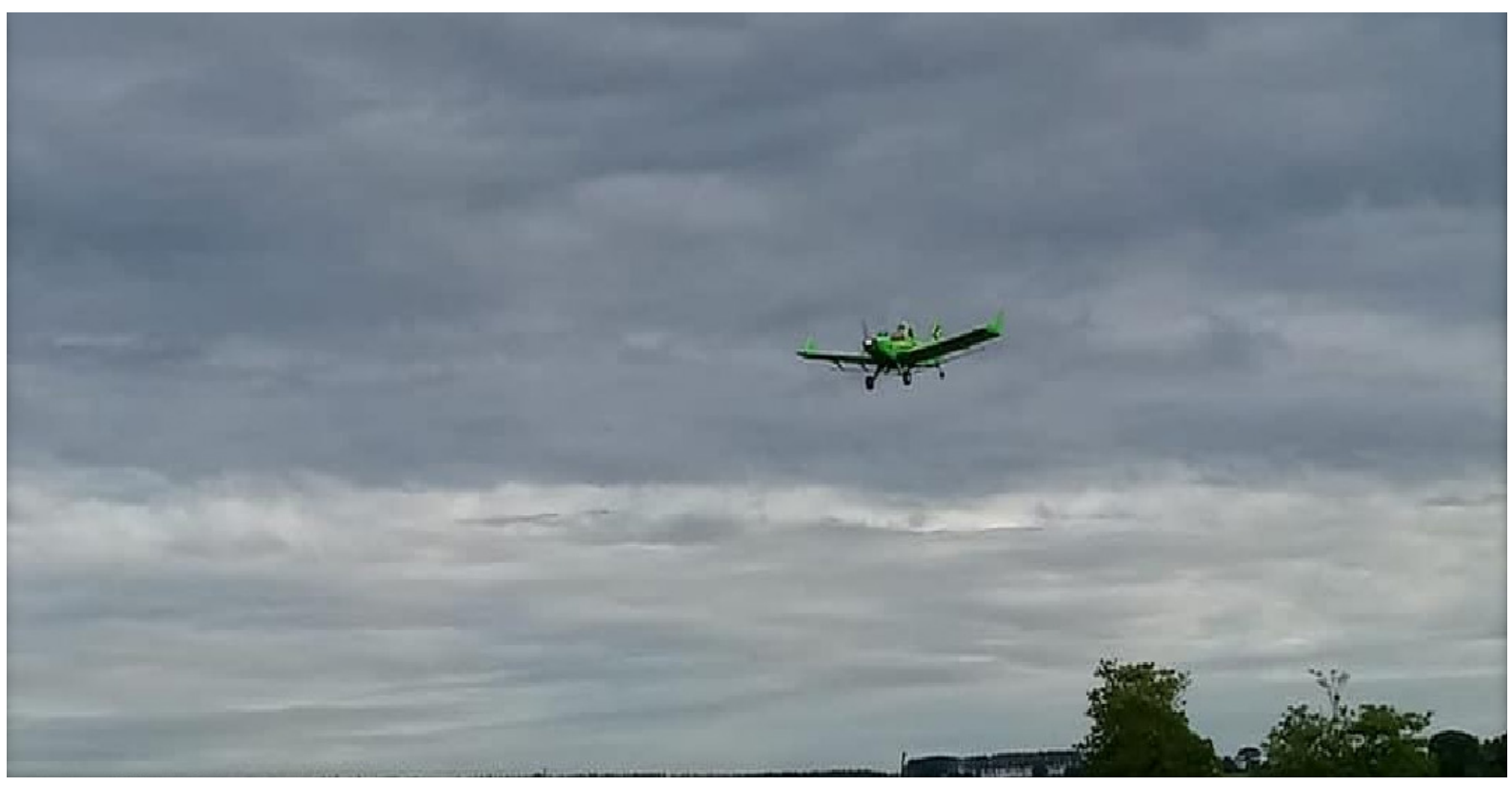

Fonte: Plizzari, P. (2015).

A imagem acima retrata a realidade vivenciada pelos camponeses no assentamento Betel e Comunidade camponesa estrelinha. A fotografia da aeronave foi registrada por P. camponês residente no assentamento Betel.

Segundo P. neste dia ocorreu um grande índice de contaminação do bicho-da-seda. 
Nesse dia, era uma tardezinha já, eu tava tirando amoreira pra tratar dos bichos, quando escutei o ronco do aviáo. Ele veio e fez uma vorta aqui em cima do barracáo. Mais ele disligou o veneno lá atrais, só que tava ventado ao nosso favor, então o vento trouxe muito veneno pra cá pra dentro (entrevista realizada no dia 17/08/2018).

Um dos principais pontos negativos associados a essa atividade é a deriva da pulverização, causada principalmente pela ação do vento, temperatura do ar, umidade relativa do ar, distância do alvo, velocidade de aplicação, tamanho das gotas, entre outros fatores. A deriva perigosa é o movimento do produto químico para fora da área intencionada e é originada das gotas que, após serem emitidas pelo bico de pulverização, flutuam no vento por um determinado período?.

A problemática se tornou tão agravante que culminou em audiência pública na assembleia legislativa de Mato Grosso do Sul em novembro de 2015. Na ocasiáo, autoridades, produtores rurais, representantes de empresas aéreas, e da sociedade civil, debateram as normas que regem a atividade no estado e as dificuldades de fiscalização e combate aos danos causados pela aplicação irregular dos produtos químicos.

Importante enfatizar o relato do sericicultor, Paulo Plizzari, residente no município de Glória de Dourados, mais precisamente no assentamento Betel. Durante a audiência, Paulo relatou sua realidade sentida na "pele" em relação aos problemas causados através da pulverização nos canaviais que se encontram no entorno de sua propriedade. Ele perdeu toda sua criaçáo de bicho-da-seda, após aplicação de agrotóxicos feita por aeronaves no canavial ao lado.

Dessa maneira, os encaminhamentos sobre o tema foram debatidos num primeiro momento, em audiência pública, através da câmera legislativa, de modo que contou com diversas autoridades políticas, representantes do ministério público estadual e federal, empresários, e os principais envolvidos diretamente sobre tal situação, os produtores familiares, representado pelo sericicultor do assentamento Betel, município de Glória de Dourados.

Essa audiência teve como objetivo debater sobre a forma que está sendo evidenciada a prática de pulverização aérea no estado de Mato Grosso do Sul, e a maneira que a fiscalização está agindo em decorrência dos fatos. A mobilizaçáo destes produtores fez com que no final de 2016 fosse aprovada lei municipal, (figura 01) (Lei No 1087 de 23 de novembro de 2016) que "dispóe a proibição de uso de pulverização aérea de agrotóxicos no município de Gloria de Dourados e dá outras providencias". No entanto, é necessário ainda a sua regulamentação.

9 Fonte: http://agenciabrasil.ebc.com.br/geral/noticia/2016-07/pulverizacao-aerea-de-agrotoxico-provoca- danos-persistentes-dizem 
Figura: 01 - Lei municipal que proíbe a pulverização aérea no município de Glória de Dourados

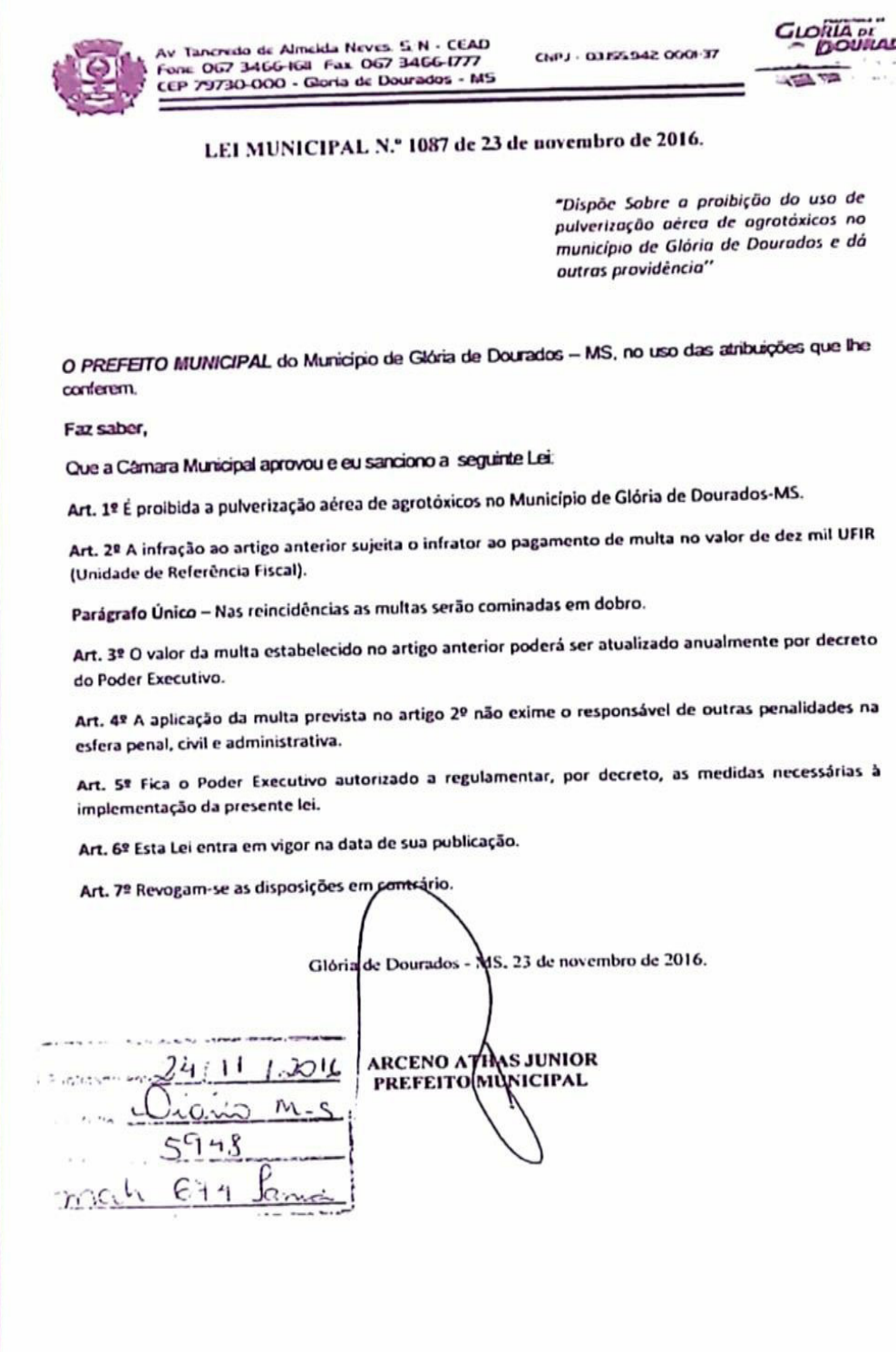

Apesar dos seguidos esforços realizados para a solução do impasse que afeta grandemente a atividade dos sericicultores, as pulverizaçôes aéreas ainda persistem na região. Isto fez com que uma comissão formada pelos prejudicados procurasse a imprensa para divulgar o caso.

Dessa maneira, os encaminhamentos sobre o tema foram debatidos num primeiro momento, em audiência pública, através da câmera legislativa, de modo que contou com diversas autoridades políticas, representantes do ministério público estadual e federal, empresários, e os principais envolvidos diretamente sobre tal situaçáo, os produtores familiares, representado pelo sericicultor do assentamento Betel, município de Glória de Dourados. Essa audiência teve como objetivo debater sobre a forma que está sendo evidenciada a prática de pulverização aérea no estado de Mato Grosso do Sul, e a maneira que a fiscalização está agindo em decorrência dos fatos.

Um dos temas de grande relevância debatido durante a audiência, se pautou na regulação e normas de aplicação aéreas no âmbito estadual e o aumento da faixa de exclusão de 500 metros para 6 quilômetros, garantindo assim uma maior segurança e preservação no contexto socioambiental. Mesmo que a legislaçáo federal (lei: 7.802/1989) prevê a distância de 500 metros como limites para 
pulverização, há estados com legislações mais restritas, ou seja, existem unidades da federação que aplicam limites de até 10 quilômetros para pulverização, outras, se aplicam a faixa de exclusão de acordo com a classificação toxicológica dos agrotóxicos, afirmou o então promotor de justiça Victor Leonardo de Miranda Taveira, do Ministério público de Mato Grosso do Sul (MP/MS) (ver matéria nos anexos de nosso trabalho). Esta situação requer muita atenção, de modo que vem gerando muitos debates a partir daqueles que defendem o uso e a ampliação dos agroquímicos e os que são contrários. Neste sentido, o uso inadequado e indevido de agrotóxicos tem se tornado não somenteum problema ambiental e/ou econômico, mas principalmente uma problemática social, no contexto de colocar em risco a saúde das pessoas, com ênfase aos camponeses residentes no campo, como comenta Camacho (2014).

É notável como vem aumentando a quantidade do uso desses insumos ao longo do tempo. Esse aumento é alvo de críticas por parte de entidades preocupadas com o bem-estar das pessoas e do meio-ambiente no campo. O emprego desses insumos tem como consequência a poluiçáo dos rios e dos solos, causando a morte de peixes e comprometendo a reprodução das comunidades ribeirinhas que tem na pesca uma atividade principal ou complementar de sua subsistência. Outro fator relevante é que esses insumos agroquímicos não ofendem somente a natureza, mas atingem diretamente a saúde dos moradores e/ou trabalhadores do campo (CAMACHO, 2014, p.05).

Consideramos ser fundamental discutir as formas como esses camponeses estão resistindo. Dessa maneira, isso fica mais evidente quando dialogamos com camponeses sobre essa "pressão" exercida, principalmente, pelo monocultivo da cana ao redor das pequenas propriedades. Então, quando lhe é perguntado, se ele pensa ou já pensou em vender a propriedade, a resposta é imediata:

Não, nunca, essa terra é nossa vida, aqui plantamos o milho, temos uma hortinha, criamos porco, galinhas, temos ovinho a hora que queremos, aqui eu acordo de madrugada pra tirar um leitinho, tratar dos porcos, mexer com minhas abelhinhas, ninguém manda no meu horário, nem no meu trabalho, aqui eu faço o que eu quero do jeito que eu quero, isso não tem dinheiro no mundo que paga. Mais eles, esses daí, do tal agronegócio não táo nem aí com a gente, querem tocar nóis daqui de todo jeito meu fío (P.P, assentamento Betel, 24/08/2018).

A foto 04 é o retrato dessa complexidade, de modo que o camponês, que além de exercer outras atividades em sua propriedade, também realiza a atividade da apicultura, cuja sua produção de mel de abelha, torna-se uma renda complementar a partir da venda de seu excedente. Neste sentido, sua atividade está comprometida e praticamente limitada ao desenvolvimento, visto que sua propriedade se encontra "ilhada" ao cultivo da cana, de modo que a utilização de agrotóxicos e outros agroquímicos (mesmo sendo utilizados tratores na pulverização) tem eliminado grande parte de suas abelhas, prejudicando diretamente sua produção. 
Foto: 04 - Plantações de cana no entorno da propriedade do apicultor em Glória de Dourados.

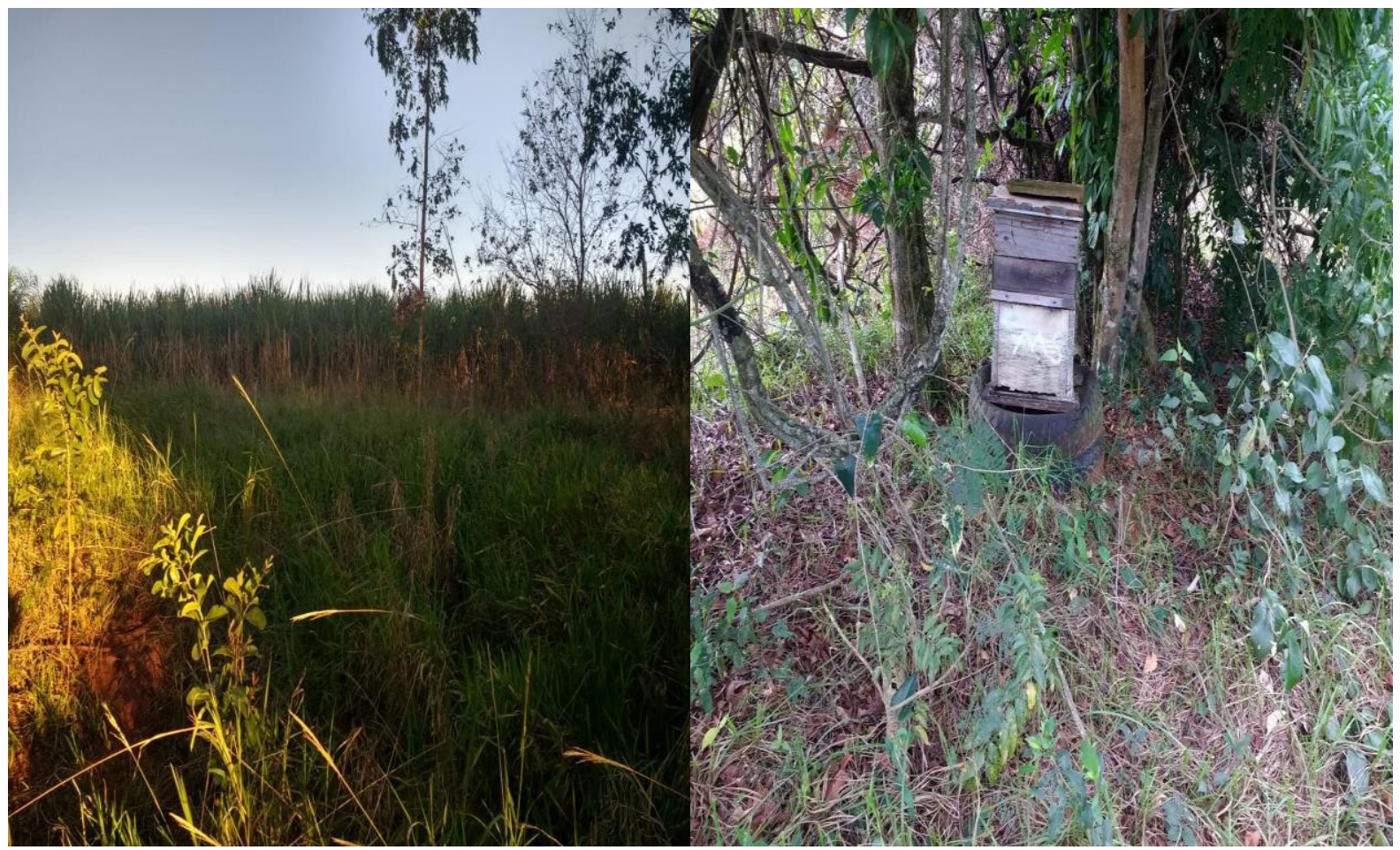

Fonte: Pereira, C. S (2019).

O camponês $M$, que tem sua propriedade próxima ao assentamento Betel, reside no local há mais de 30 anos e atualmente vem enfrentando alguns problemas com a chegada da cana na regiáo. Essa família tem como fonte de renda principal a pecuária, porém faz o complemento através da apicultura, cuja produção reduziu gradativamente nos últimos três anos a partir da intensificação e utilização de agrotóxicos.

Já faz três anos que minha produção de mel vem reduzindo, esse ano acho que nem vou colher, tudo isso provocado pelo efeito do veneno, minha área é de 30 alqueire, de um lado tem cana do outro também, eu tô cercado não tem pra onde corrê, antes da cana era soja e criação de gado, eu nunca tive problema, mais depois que chegou essa...tudo mudou, ainda bem que temos um gadinho, eu sô aposentado a muié também, sinão, num sei o que seria de nóis.

Sobre a apicultura, essa é uma atividade de grande importância, pois apresenta uma alternativa de ocupação e renda para os camponeses. É uma atividade de fácil manutenção e de baixo custo inicial em relação às demais atividades agropecuárias. Além do mais, torna-se de grande relevância dentro do contexto ambiental, pelo fato de as abelhas atuarem como polinizadores naturais de espécies nativas e cultivadas, preservando-as e consequentemente contribuindo para o equilíbrio do ecossistema e manutenção da biodiversidade.

Neste sentido, as atividades desenvolvidas pelo campesinato tornam-se de fundamental importância para o contexto socioambiental. Desse modo, compreendemos que as adversidades que envolvem os embates da questão agrária precisam ser analisadas a partir de diferentes paradigmas, com ênfase para o desenvolvimento de uma produção diversificada e eficaz no campo. 
Verificamos, ao longo de nosso trabalho, os impactos sociais e econômicos apresentados a partir da ocupação e expansão da produção canavieira no entorno do assentamento Betel e comunidade Estrelinha no município de Glória de Dourados de modo a evidenciar uma nova dinâmica na vida dos camponeses.

A resistência, luta e permanência ficam marcadas no contexto de buscarem por melhores condições de desenvolvimento em relação às atividades camponesas. Foram analisadas as condiçôes e o modo de convivência dos camponeses através da organização dos seus meios produtivos.

As manifestaçôes coletivas no assentamento Betel e na comunidade do Estrelinha foram uma importante forma de luta para garantir sua permanência na terra. A participação dos camponeses durante as mobilizaçóes e reinvindicaçóes foram de extrema relevância na perspectiva de justificarem os impactos sofridos através do uso indevido de agrotóxicos nos canaviais ao redor de suas propriedades.

As manifestações, protestos e denúncias despertaram a preocupação dos órgãos de justiça, municipal e estadual, além de audiências públicas, (anexo 01) com participaçáo de várias autoridades para discutir a problemática evidenciada entre os camponeses e os produtores de cana, que arrendam terras através da usina Adecoagro, com instalação no município de Ivinhema, MS.

Desse modo, observou-se durante a construção e a produção deste trabalho, uma realidade que se apresenta de maneira desigual em relação à ocupação e ao desenvolvimento das atividades no campo. Isso ficou evidente quando apresentamos dados informativos em relação à territorialização do capital canavieiro dentro do munícipio de Glória de Dourados e, principalmente, sobre seus impactos causados aos assentados do Betel e na comunidade de camponeses do Estrelinha.

\section{REFERÊNCIAS BIBLIOGRÁFICAS}

RIGOTTO, Raquel Maria e ROSA, Islene Ferreira. Agrotóxicos (p.88-96); Dicionário da Educação do Campo. / Organizado por Roseli Salete Caldart, Isabel Brasil Pereira, Paulo Alentejano e Gaudêncio Frigotto. - Rio de Janeiro, São Paulo: Escola Politécnica de Saúde Joaquim Venâncio, Expressão Popular, 2012. 788 p.

BOMBARDI, Larissa Mies - Geografia do Uso de Agrotóxicos no Brasil e Conexões com a União Europeia / Larissa Mies Bombardi. - São Paulo: FFLCH - USP, 2017. 296 p.

BRASIL, Lei No 7.802, de 11 de julho de 1989. Disponível em: www.ucs.br , etc > simposioinovacaoagronegocioucs, paper, viewFile. Acesso em: 22 abr. 2016.

CAMACHO, Rodrigo Simão. Algumas consideraçóes acerca do modo de vida camponês.

Fórum Ambiental da Alta Paulista, v.10, p.1 - 16, 2014.

COSTA, Cinthia Cabral da. Custo e benefícios do uso da pulverização aérea de agrotóxicos na agricultura / Cinthia Cabral da Costa. - São Carlos: Embrapa Instrumentação, 2017.

http://agenciabrasil.ebc.com.br/geral/noticia/2016-07/pulverizacao-aerea-de-agrotoxico- provoca-danos-persistentes-dizem especialistas (Publicado em 16/07/2016 - Por Edwirges Nogueira - Repórter da Agência Brasil. 


\section{ANEXOS}

Anexo 01: Audiência pública e encaminhamentos

Zeca do PT denuncia uso indiscriminado de agrotóxicos e sugere debate sobre o tema

Cómuro, PI, plenäria, Zeca do PT, agrotóxicos, Ministério Publico Federol, pulverizosäo, Mato Grossedo Sul indigena, pequenos produtores.

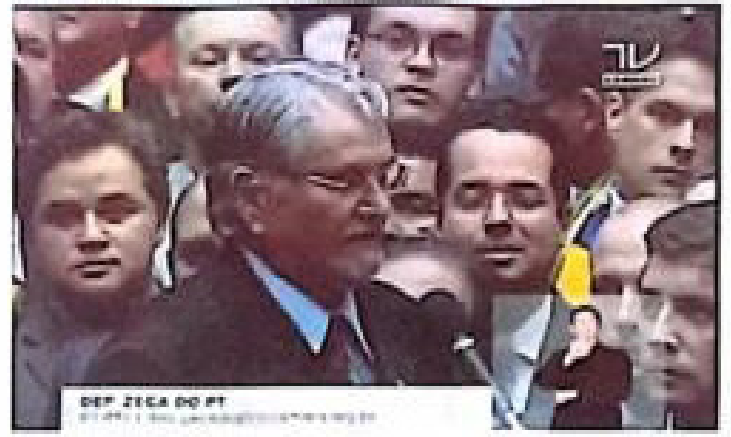

O deputado Zeca do PT (PT-MS) anuneiou, em pronunciamento no plenátio, que vai solicitar ao Ministério Público que investigue e apure a utilizaçăo de venenos nāo autorizados pela Agència Nacional de Vigillåncia Sanitäria (Anvisa) nas lavouras de soja, particularmente, no Mato Grosso do Sul. Tem sido um desastre, no Mato Grosso do Sul, a contaminaçāo por pulverizaçå aétea das lavouras, acabando com a saúde do povo es pequenos produtores de bicho de seda e mel", afirmou.

De acordo com o parlamentar petista, hà tempos ele vem denunciando o uso indiscriminado de agrotóxicos. "Levantamos essa discussăo em 2015, no seminário proposto por nosso mandato em parcetia com Càmara dos Deputados sobre o tema dos impactos dos agrotóxicos na sociedade. Na época foi proposta uma legislaçăo mais rigida contra esse tipo de situaçăo, que acredito ser um crime contra natureta e contra os pequenos produtores, que săo desrespeitados pelos grandes latifundários da soja e da cana de açucar", explicou. Zeca do PT disse que a pulverizaça atrea irregular trat nåo só prejuizos económicos mas. também, ameaça a vida das pessoas. "Em outubro de 2016, o Ministerrio Püblico federal (MPF) denunciou um piloto de um aviふo agricola que pulverizou uma plantação de soja a menos de 12 metros da aldeia indigena Guyra Kambry, na regiaio de Dourados, colocando em risco a saúde desta popula šso inteira", destacou o petista.

Segundo o Ministério Público, acrescentou Zeca do PT, "atualmente a legislaç̧o federal sobre o tema tem como limite apenas 500 metros de distíncia de povosçðes, cidades, vilas ou mananciais de água para pulverização aérea de determinada ărea. Em alguns estados esta exigència minima é de 10 quilômetros ou de acorđo com classificação do veneno".

O parlamentar petista defende um debate aprofundado sobre o terna do uso dos agrotóxicos. "Epreciso set rediscutido a fundo a queståo dos agrotóxicos no Brasil, e imediatamente a quest’̊o da pulverizaçăo aérea, com mudanças na legislą̧̃o que as deixem as normais mais rigidas e que garantam uma fiscalizaçăo efetiva sobre as empresas que prestam esse tipo de serviço para que caso houver o descumprimento delas, sejam punidas com rigor", enfatizou Zeca do PT. 
Na última terça, 8 de novembro, foi realizada, em Campo Grande (MS), audiẻncia pública para debater o aperfeiçoamento da legislação sobre pulverizaşão aérea de agrotóxicos. Autoridades, produtores rurais, representantes de empresas aéreas e da sociedade civil debateram as normas que regem a atividade no estado $\mathrm{e}$ as dificuldades de fiscalizaçăo e combate aos danos causados pela aplicação itregular dos produtos.

O debate público aconteceu na Assembleia Legislativa de Mato Grosso do Sul e concluiu pela necessidade de ręulaçāo, em ámbito estadual, da aplicação de agrotóxicos por aeronaves $e$ do aumento da faixa de exclusão, de 500 metros para 6 quilómetros, de modo a garantir a segurança da populaşajo e de preservar áreas de interesse ambiental.

- Apesar da legislação federal prever o limite de apenas 500 metros para pulverizaçảo, há estados com legislação mais restritiva. A titulo de exemplo, ternos unidades da federação cuja distáncia è de 10 quilòmetros e outras que estabelecem a faixa de exclusão conforme a classificação toxicológica dos agrotóxicos", explica o promotor de justiça Victor Leonardo de Miranda Taveira (MP/MS).

Para o procurador da república Marco Antonio Delfino de Almeida (MPF), além da preocupaşăo com o aperfeiçoamento normativo, tem-se a necessidade de incrementar as atividades de fiscalização das empresas de aviação agricola, em especial de aviōes particulares. Em Mato Grosso do Sul, segundo dados do Sindicato Nacional das Empresas de Aviação A Aericola (Sindą), existem cadastrados 100 aviōes, 16 empresas e 57 aeronaves privadas. "A atividade è hiper-regulada, mas com fiscalizaça quase inexistente. É preciso que haja o monitoramento das aeronaves e o registro público dos dados para um efetivo controle", defende o Ministério Público.

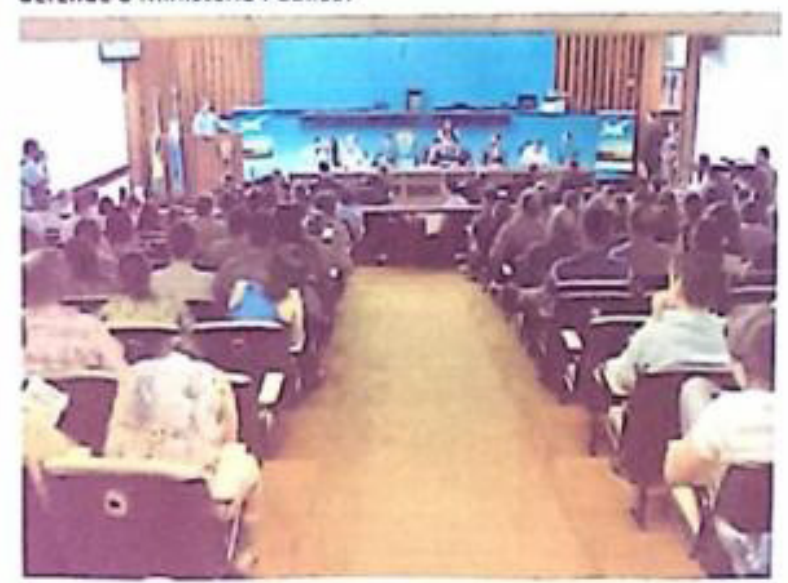

Audincia públca reuniu especialistas, empresisios e produtores no plenario da ALMS. (Foto: MPr/MS)

Precaugaso

A audiència pública, alèm das exposiçōes téenicas, contou, ainda, com o relato de um sericicultor do municipio de Glória de Dourados. Paulo Plizzari perdeu toda a criaçăo de bicho da seda após a aplicaşăo de agrotóxicos por aeronaves no canavial ao lado de sua propriedade. 
"Uma vez, o vento foi nosso amigo, mas na uiltima aplicaşăo tivemos um prejuizo de $100 \%$. Acho injusto ser expulso da minha casa por causa de uma atividade do vizinho", lamentou. Segundo o produtor, outros sericicultores da regiāo tambèm perderam suas criaçōes. "O bicho da seda è muito sensivel e a deriva que o agrotóxico deixa afeta diretamente a produçāo". afirma. A detiva, quando a aplicação de defensivo agricola não atinge o local desejado e se espalha para outras áreas, é um dos principais riscos da pulverização aérea.

De acordo com a pesquisadora Alexandra Penedo de Pinho (UFMS), ainda são desconhecidos cientificamente todos os impactos dos agrotóxicos no meio ambiente e na saúde humana, motivo pelo qual sua utilizą̧ão deve ser cautelosa, como esclarece o promotor Victor Taveira: "no Direito Ambiental, existern os principios da prevençăo e da precauçäo que objetivam, exatamente, evitar danos ambientais de atividades cujos impactos não sejam cientificamente identificados e mensurados".

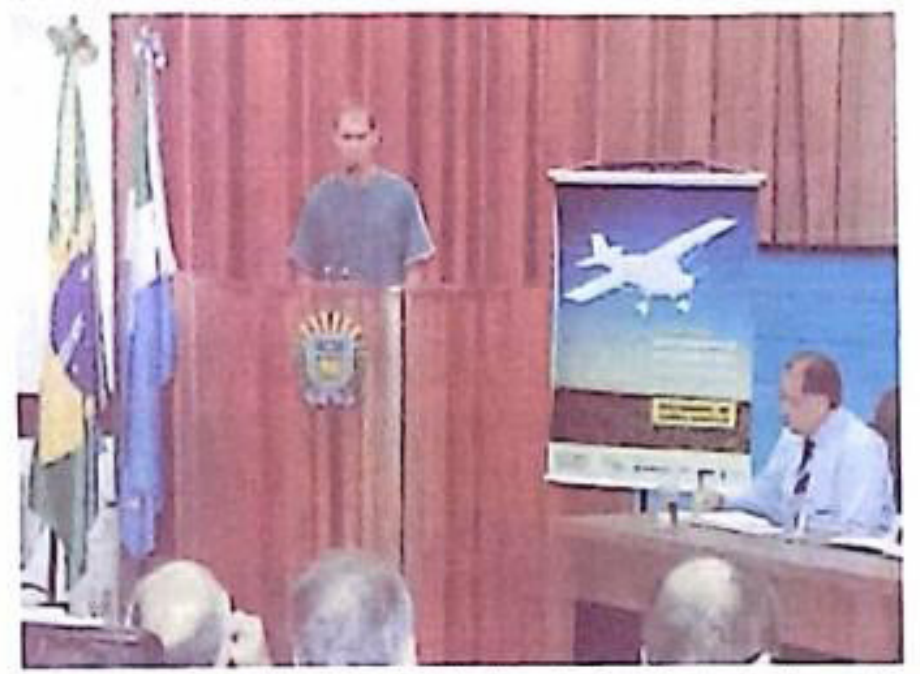

Sericicultor perdeu toda a crią̧a de bicho da seda após pulverizaçăo de agrotóxicos em canavial vizinho. (Foto: MPF/MS)

\section{Encaminhamentos}

Alèm das alteraçōes legislativas $\mathrm{e} O$ aumento na fiscalização, a audiência pública tambẻm teve como encaminhamentos a proibição de pulverização área na Bacia do Alto Paraguai e na Bacia do Paraná; a obrigação de que os empreendimentos que utilizam agrotóxicos façam monitoramento dos residuos nos cursos d'água, na vegetaçäo nativa e nas aglomeraçōes urbanas; $\mathrm{e}$ o dever de informaçāo prévia às comunidades possivelmente afetadas pela aplicação aérea dos agrotóxicos.

A audiência pública foi proposta pelo deputado Amarildo Cruz (PT), em parceria com o Ministério Público Estadual (MPE), Ministério Público Federal (MPF), Ministério Público do Trabalho (MPT) e a Comissão de Combate aos Impactos de Agrotóxicos no Estado. 
Audiência Pública em Glória de Dourados (MS) discute apllicaçăo atrea de agrotóxicos em canavlals

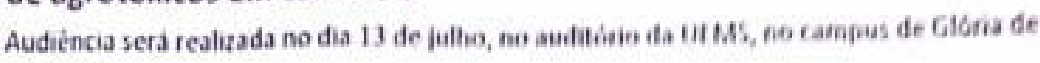
Dourados

O Ministerio Püblico federal em Mato Grosse do Sud (MAF/ Mas) eo Ministerno Publico de Mato Grosso do Sul (MP/MS), por meio da Prometena de lustica de Glatia de Dourados, reafizam Audiéncia Püblica para discutir os impactos ambientais, tanitanos e vocioerondmicos decorrentes da aplicaçio aérea de aprotósicos rm canavias no municipo A reunilo será realizada no dia 13 de julho, as 18 h30, no auditóno da Universidade fitadual de Mato Grosso do Sul (UEMS), em Glória de Dourados

O objetivo è debater os impactos da aplicaça acrea de agrotóvicos em canaviais da regiăo e seus efeitos juridicos, técnicos e de gestão participativa. 0 encontro visa, ainda, buscar esclarecimentos que possam sustentar as açōes dos membros do Ministerrio Publico e permitir a manifestação dos interessados.

A audiẻncia pública será presidida por membros do MPF/MS e do MPE/MS que atuam nos municipios de Dourados e Glória de Dourados. Estǎo convidados a participar do encontro autoridades federais, estaduais e municipais diretamente interessadas no tema, operadores do Direito, académicos especialistas no tema e representantes de sociedade civil. Audięncio Pública sobre impactos ambientois, sonitrórios e socioeconهmicos decorrentes do aplicaşỗo atrea de agrotóxicos em conavials em Glória de Dourados

Doto: 13 de julho de 2016

Horb́rio: 18:30

Local: Auditório da UEMS, campus de Glório de Dourados 


\section{Seminário na Assembleia Legislativa debate Impactos dos Agrotóxicos na}

\section{Sociedade}

Por: Assessoria de imprenso do semindirio foto: Divulgaçảo

Seminátio acontecerá na próxima segunda-feira, dia 17

O Brasil é o Pais que mais utiliza agrotóxico nas plantaşões. Dados do Instituto Nacional de Cancer José Alencar Gomes da Silva (INCA). órgão do Ministério da Saúde, afirmam que no Brasil a venda de agrotóxicos saltou de US\$ 2 bilhōes para mais de US\$7 bilhôes entre $2001 \mathrm{e}$ 2003 , alcançando valores recordes de US\$ 8,5 bilhōes em 2011. Discutir os riscos à saúde e os

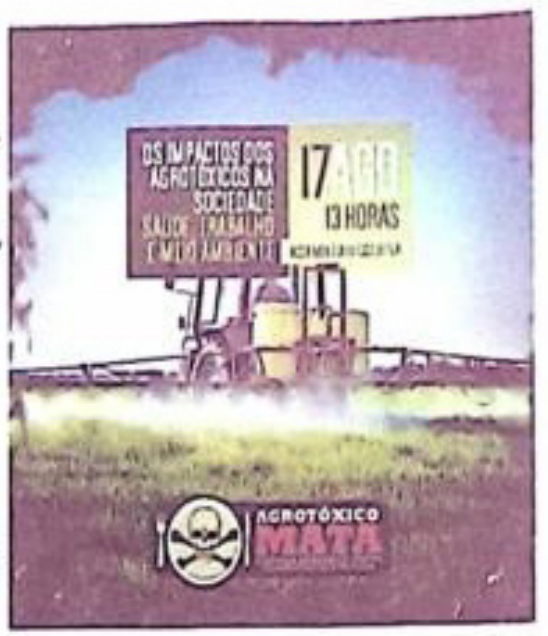
danos ambientais causados pelo uso desse produto é o objetivo de um seminário que será realizado na próxima segunda-feira, dia 17.

O evento é promovido pela Assembleia Legislativa e a Cámara federal, por meio dos deputados estaduais Amarildo Cruz (PT), Pedro Kemp (PT) e Zeca do PT, respectivamente. $O$ Serninário: Os Impactos dos Agrotóxicos na Sociedade inicia às 13 horas, e contará com a participaçăo de pesquisadores de Mato Grosso do Sul e de outros estados.

Estudos estimam que aproximadamente 25 milhōes de trabalhadores agricolas de paises pobres solram com algum tipo de intoxiçç̧̃o causada por exposição a agrotóxicos. De acordo com dados do Instituto de Defesa Agropecuária do Estado de Mato Grosso (Indea), Mato Grosso é o maior consumidor do Brasil, com o equivalente a 43 litros de veneno por habitante.

Em Mato Grosso do Sul, a estimativa é que cada pessoa consome proporcionalmente até 40 litros de agrotóxicos por ano, quase seis vezes a mais do que a média nacional per capita, que é de 7,3 litros por ano. A exposiçāo e o consumo de produtos contaminados em médio e longo prazo podem causar distúrbios neurológicos, problemas respiratórios, cardiacos, pulmonares, no sistema imunológico e na produção de hormónios, alèm de má formação fetal e até cáncer.

Conforme o deputado estadual Amarildo Cruz, estudos recentes do Inca mostram a relaçăo do crescimento das vendas de agrotóxicos com o registro de casos de caincer no Pais. "Esse é um assunto preocupante e que precisa ser discutido com profundidade e responsabilidade. $O$ Pais é o maior consumidor de agrotóxicos no Mundo. Temos o caso comprovado de intoxicaçăo de centenas de pessoas na cidade de tucas do Rio Verde, em 2006, durante uma pulverizaçăo aérea. Até hoje moradores daquele municipio sofrem com os problemas daquela intoxicaçāo", esclareceu.

Para o deputado federal Zeca do PT, a fiscalização da comercialização dos agrotóxicos deve ser 
mais rigida. "Se o consumo Brasil é alto, imagine no nosso Estado, que faz fronteira com a Bolivia e o Paraguai, É sabido que entram via fronteira diversos venenos com componentes altamente cancerigenos, sem nenhum controle da Anvisa. É preciso uma maior fiscalizaçäo", alertou Zeca do PT.

Segundo o deputado estadual Pedro Kemp (PT), é preciso discutir com urgència nẵo só o controle da utilização de agrotóxicos para minimizar as consequèncias, mas também alternativas para produção agroecológica. "Considero esta audiència pública como um importante alerta à sociedade sobre o uso exacerbado de agrotóxicos na produção agricola, que tem contaminado o solo, os recursos hidricos e o ar, acarretando comprovadamente sérios danos à saúde humana", falou.

Confira a programação:

$13 \mathrm{~h}$ - INSCRIÇĀO

13h30-ABERTURA

MESA I- DIAGNÓSTICOS E IMPACTOS DOS AGROTÓXICOS NO TRABALHO, SAÚDE E AMBIENTE

$13 \mathrm{~h} 45$ - Professor Dr"Wanderley A. Pignati - UFMT

Tema: Uma agricultura saudável é possivel: a importảncia da campanha permanente no combate ao uso de agrotóxicos:

14h10 - Pesquisador Luiz Claudio Meirelles - FlOCRUZ

Tema: 0 submundo dos agrotóxicos: consequèncias do poder econômico das empresas nacionais e multinacionais no lobby na liberaçāo de agrotóxicos

$14 \mathrm{H} 35$ - Dr" Professor Luiz Felipe Ribeiro Pinto - INCA(Instituto Nacional do Cảncer)

Tema: Agrotóxicos e suas consequências na estrutura celular: sentença morte das populações expostas.

MESA II - GARANTIAS DE CONSOLIDAÇÃO DE SISTEMAS PRODUTIVOS VIÁVEIS E SEGUROS

14H55 - Professora Drª̀rária Rizzo - UFMS

15H10 - Professor Dr* Dario Pires - UFMS

Tema:Contribuições da Quimica nas análises dos impactos no trabalho, saúde e ambiente.

$15 \mathrm{H} 25$ - Professor Dr"Denilson de Oliveira Guilherme - UCDB

Tema:Biotecnologia como Alternativa ao uso de Agrotóxicos

15 h45 - Biologo Olácio Komori - Presidente da Associação dos Produtores Orgånicos de MS APOMS

Tema: Viabilidade da Agro Ecologia na Produção de Alimentos

16 h05 - Marco Antonio Delfino de Almeida - Procurador do Ministério Público Federal

Tema: Legislaçäo sobre o uso de agrotóxicos

$16 \mathrm{~h} 25$ - Encerramento e consideraçōes finais

Leitura do documento produzido 